\title{
Staging atmosphere: collective emotional labour on the film set
}

\author{
Allan Watson \\ Geography and Environment, School of Social Sciences, Loughborough University, \\ Loughborough, LE11 3TU, UK (Corresponding author) \\ E-mail: A.Watson3@lboro.ac.uk \\ Jenna Ward \\ School of Business, University of Leicester, Leicester, LE1 7RH, UK \\ James Fair \\ Faculty of Media and Communication, Bournemouth University, Poole, BH12 5BB, UK
}

\begin{abstract}
Despite a significant multi-disciplinary body of work on emotional labour, its application to geographical debates regarding space remains thin, and the role of emotional labour in the interrelations that produce space is poorly understood. In contrast, a substantial literature has developed in social and cultural geography concerned with 'affective atmospheres', understood as the relational and collective nature of affects. Within this literature, consideration has been given to the ways in which atmospheres might be staged to affect people's moods for a variety of artistic and commercial reasons. Placing the concepts of emotional labour and atmosphere into dialogue, this paper offers a relational account of the film-set as a space in which directors, cast and crew engage in performances of individual and collective emotional labour in order to stage particular atmospheres. Drawing on primary qualitative data, we present the on-set work of film
\end{abstract}


directors as attending to three relational projects; comportment, corpsing and conflict. In so doing, this paper offers a new understanding of the staging of atmosphere through performances of collective emotional labour. Such a perspective goes beyond the material to consider the emotional qualities of space and brings agency and intentionally to the fore in accounts of atmosphere.

\section{$\underline{\text { Key words }}$}

Emotions, emotional labour, atmosphere, film, creative industries, performance

\section{Introduction}

Over the last two decades, significant attention has been paid by geographers to issues of emotion and affect (see Anderson \& Smith, 2001; Thrift, 2004; Davidson \& Bondi; 2004; Davidson \& Milligan 2004; Bondi, 2005; Davidson, Bondi \& Smith, 2005; Thien, 2005; Smith, Davidson, Cameron \& Bondi, 2009; Pile, 2010). Within this area of research, geographers have been part of a wider cross-disciplinary project exploring emotional labour in a variety of work settings and organisational contexts (see for example Crang, 1994; McDowell, 2001; Wellington \& Bryson, 2001; Bryson, 2007; Dyer, McDowell \& Batnitzky, 2008; Batnitzky \& McDowell, 2011). However, while space is recognised as a product of interrelations, and emotions as central to how one relates to others in and through emergent and transformative experiences (Thrift, 2008), the application of the emotional labour concept (Hochschild, 1983) to geographical debates regarding space remains surprisingly thin.

In contrast, a substantial literature has developed in social and cultural geography concerned with 'affective atmospheres', building on non-representational theory and on the body 
of geographical literature on affect and emotion. This work has offered important ways of thinking about the social, political and economic production of space and place, and in particular the dynamic and kinetic relations between bodies and spaces (see McCormack, 2008; Ash, 2013; Bille, Bjerregaard \& Sørenson, 2015). More recently, work on atmospheres has given consideration toconsidered how they might be staged to affect people's emotions (see for example Edensor, 2012, 2015). As Bille et al. (2015) suggest, the notion of 'staging' a phenomenon as fleeting and ambiguous as an atmosphere might seem paradoxical. Yet they note that-various actors may seek to do so to create emotional responses, affect people's moods and guide behaviours, for a variety of aesthetic, artistic or commercial reasons.

In this paper, we draw on the notion of 'staging' ef-atmospheres as a framework through wich-to draw work on emotions into closer dialogue with geographical work on atmospheres. Specifically, we consider how emotional labour, which involves the "management of feeling to create a publicly observable facial and bodily display” (Hochschild, 1983; p. 7), can be used as an active and intentional strategy for staging atmospheres. We do this through an in-depth examination of a very particular space, the film set; exploring, to examine-the ways in which film directors understand and manage the role of emotions in staging an atmosphere on set. It has been argued elsewhere that the film-set is a particularly pertinent focus for emotions research because it is an emotionally-charged, time-pressured, action-oriented, highly fluid space of performance and work (Coget, Haag \& Gibson, 2011), emergent through a very specific set of professional, performative, technical and creative relations and interactions.

Conceptually, we argue that bringing Hochschild's emotional labour construct into dialogue with the literature on atmospheres provides a more fluid conceptualisation of emotions and space, and allowsing for the development of a post-structuralist critique of the notion of 
fixed emotional 'frames' (Goffman,-(1959). This allows us to provide an alternative affective reading of the dramaturgical space of the film set as one in which the 'frames' of action and perception, feeling and display, front and back stage are effectively blurred. In this alternatively conceptualised affective and relational space we demonstrate the importance of emotional labour, and in particular collective emotional labour, to film directors' management of the film set. We identify three relational projects in this regard: comportment, corpsing and conflict, which taken together offer new insights in to the role of emotions and emotional labour in creating and maintaining atmospheres. Thus, this paper contributes to the development of a more nuanced understanding of the conceptual links-relationship between emotional labour and atmosphere.

As well as contributing to the geographical literature on emotions and atmosphere, we also make an important contribution to the sub-discipline of film geography. Significant bodies of geographical literature now exist on film as cultural text (see for example Clarke \& Doel, 2007; Doel \& Clarke, 2007; Dodds, 2013) and, engaging with spaces of film production from a eultural studies angle, onand on landscape and production location (see for example Mathews, 2010; Lukinbeal, 2012). Yet, while the material and technical elements of production have received significant attention, to date there has been scant consideration of spaces of production in terms of their emotional qualities. It is to this task that we attend in this paper. While we concentrate specifically on the film set, it is important to note that the emotional qualities of film go well beyond its spaces of production. Sharp and Lukinbeal (2015) note the role of haptic and affective theories in helping to conceptualise film viewing as an emotional bodily experience; Tan’s (1996) work on film as an 'emotion machine' for example highlights the importance of the empathetic emotions of the viewing subject in relation to characters. Thus, one must consider the 
emotions of performance in bringing the film’s meaning into being.; Iindeed, as Ostrowska (2010; no pagination) notes, "the magic of cinema is in the emotions experienced not only by the spectators but also by their makers during the process of film-production”.

\section{Actors, audiences, and atmospheres}

With respect to undertaking research on the film-set as affective and emotional space, the work of Erving Goffman provides an interesting point of departure given his commitment to understanding, analysing and describing social interactions and encounters through the metaphor of dramaturgy. Renowned for his systematic conceptualisations of minute social experiences, Goffman's focus is on the implicit rules that define the organisation of everyday behaviourfather than on the interactions themselves per se that take place within particular social situations. Goffman (1974) used the term 'frame' to refer to the "inevitably relational dimensions of meaning” (p. xiii). Meaning is not fixed but perceived; but how meaning is perceived is not random or accidental or even individual but is instead defined by implicit or unstated rules and principles. Goffman's (1959) reference to 'impression management' draws upon a dramaturgical reading of social life, in which individuals 'perform' roles, behaviours and relationships with a continual consciousness of an audience; they perform or manage the impressions of others. In short, and controversially, Goffman’s ontological position is one where the self only 'acts' when there is an audience to appreciate and co-construct the performance, that is to say that it occurs in the context of an appropriate frame (Goffman, 1974). The self is a 'dramatic effect'. The actor has little agency or capacity to feel or act outside of the social establishment or implicit social rules of a particular interaction,-and is instead a metaphorically physical "peg” (1959, p. 245) upon which the props, costumes and characters can be hung. 
Many scholars have challenged the passivity of such an ontology (Blumer, 1969; Hochschild, 1983) questioning how it is possible for the self to be reduced to such low-level passivity whilst continuing to be governed or influenced-by social rules. Despite, drawing heavily on Goffman (1959) to inform her conceptualisations of surface and deep_acting-acting and indeed the fundamental premise of institutional control over private emotions in her emotional labour thesis, Hochschild, is perhaps one of Goffman's harshest critics in this regard. For Hochschild, the self has to be a subject of "emotive experience” (1983, p. 217). In other words, Goffman's actors might manage external displays of feelings in order to comply with display rules (Ekman, 1973) but they have no capacity to manage internally felt emotions. In her own words, "[For Goffman] Feelings are contributions to interactions via the passive medium of a bodily self. We act behaviourally, not affectively. The system affects our behaviour, not our feelings” (Hochschild, 1983, p. 218). Hochschild's (1979) conceptualisation of feeling rules was a way of addressing her discontent with Goffman's ontological position. Significantly, emotional labour recognises the value of regulating one's own emotions in accordance with "situational dictates” (Kruml \& Geddes, 2000, p. 11) or what she termed 'feeling rules' (Hochschild, 1979). Effective emotional labour performances not only require an implicit knowledge of the appropriate display rules (Ekman, 1973) as Goffman would assert, but of-feeling rules (Hochschild, 1979)-too. However, emotional labour is not only about the inducement or suppression of one's own emotions, but in so doing the ability to "produce the proper state of mind in others" (Hochschild, 1983, p. 7). In other words, the ability to elicit appropriate emotional responses from others requires a performance in which your own emotions are managed. 
The idea of "a proper state of mind in others" (emphasis added) marks an important yet subtle difference in Goffman and Hochschild's positions-here toø. Goffman's metaphorical exploration of the 'theatrical frame' is insightful in understanding his perceptions of the 'theatre' as a workspace. However, it also reveals a particularity in that 'presentation of the self' is always in respect of the audience, third party or whom Goffman refers to as "onlookers” (1974, p. 226). The dramaturgical metaphor is pervasive yet it focuses on a one-dimensional presentation of dramaturgy (for the audience). Indeed, Goffman's work focuses in incredible depth and detail-on the ways in which theatrical performances are experienced and understood as "voluntarily supported benign fabrications” (1974, p. 136) but this fails to consider relationships that exist in that space beyond that of audience's interpretations. It says nothing of the complex work spaces, of the performative space and importantly of the interrelations required to create and maintain such performances, i.e. the relational space.

The traditional dramaturgical reading offered by Goffman sees space as-divided into two kinds of -bounded areas: "front regions where a particular performance is or may be in progress, and back regions where action occurs that is related to the performance but inconsistent with the appearance fostered by the performance” (Goffman, 1959, p. 135). Wulff for example, in her account of performance in ballet, describes the contrast between the "polished illusion on stage" and the "intense world backstage" that is mostly hidden from the audience (1998, p. 109). In the case of ballet, and of course theatre, which is the basis of Goffman's metaphorical analysis-these spaces are largely physically separated; on- and off-stage. Yet, the film set differs from such spaces in that it is a singular physical space of both technical work and creative and artistic performance. Whilst one might consider there to be a difference in the nature of work between being in front of the camera as an actor or behind the camera as director or crew, there is no 
formal or physical separation or 'boundary' between the two activities. The lack of physical bounding or separation-problematizes the binary construction of the front-back region as set out by Goffman (1959). Whilst Hochschild (1983) adopts the dramaturgical metaphor to explain the ways in which emotional labourers would attempt to relieve themselves of the burden of performing and managing their own emotions and the feelings of those around them by physically moving to less visible spaces, i.e. go back-stage, for her the dramaturgy is twodimensional (for self and audience). To produce and maintain a performance either in a theatre, on set or indeed in social everyday interactions is not an individualised endeavour. Instead it relies on the collective performances of others to adhere to appropriate display and feeling rules.

When placed in dialogue with the more recent literatures on atmospheres (Wetherell, 2012), the passivity of Goffman's actor can be extended to include the passivity of the relational space and the interactions that emerge. Collective emotional labour, then, offers an interesting third-dimension to the production of affective atmospheres in relational work spaces (self, audience, cast and crew). Further, the concept of atmosphere offers a less static and-more fluid conceptual device than that offered by Goffman's dramaturgical reading. With roots in nonrepresentational geography and affect theory, wWe find the concept to be particularly applicable to the case of the emotional space of the film set for three reasons. First, underpinning this concept is the understanding that affect is distributed amongst various elements across space, with atmospheres being "temporary configurations of energy and feeling" (Conradson \& Latham, 2007; p. 238). Thus, 'atmosphere' is an inherently relational concept_, and one-which we find transfers well to collaborative spaces of creative performance and work such as the film set. Second, it is also af extremely dynamic concept; as Anderson (2009; p. 79) notes “atmospheres are perpetually forming and deforming, appearing and disappearing, as bodies 
enter into relation with one another. They are never finished, static or at rest.” As we shall subsequently demonstrate through our empirical account, thisThis dynamic quality is an important characteristic of the affective space of the film set and the emotional aspects of film production. Finally, as Bille et al. (2015) note, atmospheres cannot be reduced to the meanings produced by the persons and objects that are part of their realisation, but rather are "instrumental in rubbing out the boundaries of its various components” (2015; p. 33). This notion we find to be particularly applicable to problematizing the binary construction of regions developed in Goffman's accounts in the context of the film set.

\section{Collective emotional labour and the staging of atmospheres}

Most studies of emotional labour take a highly individualised perspective on the emotional labour construct, and emotional labour performances tend to be thought of and theorised as if the emotional labourer has agential control over his or her own emotions and, if effectively performed, control over the emotions of the service recipient too (McMurray \& Ward, 2014). In this way, emotional labour interactions are positioned as taking place in a vacuum, away from the wider social context, organisational environment and other interactions and relations. This conceptual trajectory, however, is not borne out of Hochschild's (1983) original conceptualisation of emotional labour. In fact,Rather, Hochschild makes specific reference to the importance of “collective emotional labour” performances-(1983, pp. 114-116) by highlighting that the work of flight attendants is partly an “emotional tone' roadshow" $(1983$, p. 115), In this way, collective emotionalwith emotional labour being-is important relational work that takes place between workers to help maintain a particular 'atmosphere'. As Edensor (2012; p. 1105) notes, various states of emotion are identifiable as “communicable, inter-subjective states”. 
Individuals participate in the creation of atmosphere through their moods; while these atmospheres act to attune mood, they are simultaneously the extendedness of our moods (Edensor, 2015). In what follows, we explore how collective emotional labour performances are important to the work of film directors in ways which offer new insights into the intentional staging of atmospheres.

We find Hochschild's (1983) emotional labour thesis particularly productive when placed in dialogue with the literature on the staging of atmospheres. While-Given that emotional labour is noted not only as "the management of feeling to create a publicly observable facial and bodily display", it is not only about the inducement or suppression of one's own emotions, but in so doing the ability to "produce the proper state of mind in others" (Hochschild, 1983, p. 7) 2 . In other words, emotional labour underpins the ability to elicit appropriate emotional responses from others, but requires a performance in which your own emotions are managed. We argue, then, that the eoncept notion of the 'staging' ef-atmospheres that aeffect mood is intimately linked with the emotional labour construct. Indeed, we note that explicit references to the creation of an 'atmosphere' in particular spatial contexts are made in many accounts of emotional labour; see for example Sharma and Black (2001), on the emotional labour of beauty therapists in creating relaxing atmospheres in the salon, and Isenbarger and Zembylas (2006) on emotional labour creating atmospheres of caring and acceptance in the classroom. The notion of being able to create "a proper state of mind in others" (Hochschild, 1983, p. 7, emphasis added) through emotional labour marks an important yet subtle difference between Hochschild's position and the traditional dramaturgical reading of Goffman. The dramaturgical metaphor is pervasive yet it focuses on a one-dimensional presentation of dramaturgy (for the audience). It says nothing of the complexity of work spaces and importantly of the interrelations required to 
stage and maintain atmospheres. The creation of atmosphere, for example may not be solely be for an audience. Rather, it may also act as a form of coping mechanism for those performing the emotional labour. Bolton (2001; p. 96) for example examines how nurses may create a 'playful' atmosphere on the hospital ward allowing for 'daft' behaviour as part of creating “their own coping mechanisms, their own methods of letting off steam and their own ways of presenting the 'correct face'”. For Hochschild, the dramaturgy is two-dimensional - for the audience, but also for self.

Turning to our own research and the specific caseon settings of creative performance settings, Eextant research on emotions and creativity has focused almost exclusively upon emotional and bodily performances and emotional-relations between performers and their audiences (see for example Konijn, 1991; Shannon, 2003; Morton, 2005; Duffy, Waitt, GormanMurray \& Gibson, 2011). Such accounts align with a one-dimensional dramaturgical reading of

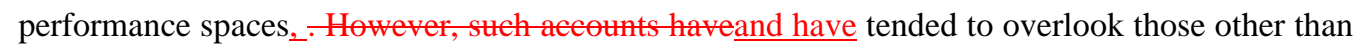
Comment [J W1]: Does this work? We refer to our previous work but then do not cite it or go into detail... Should the sentence just start with 'Extant research

the performers working in these creative and performance spaces. There are a limited number of accounts of the emotional labour performed by directors and producers - the people who manage, lead, support, and encourage the technical and emotional elements of creative performance - or indeed the 'below the line labour' (Mayer, 2011) of others not in directing or producing roles that make creative production possible (c.f. Grindstaff, 2002; Hesmondhalgh \& Baker, 2008; and Soronen, 2017). Watson and Ward (2013) for example consider the emotional labour performances of recording studio producers and engineers in (re)creating the studio as a space which allows musicians to produceof emotional performances. They describe this in terms of 'creating the right vibe', where 'vibe' is considered to be “a combination of both a relaxed atmosphere and an open and creative relationship between the producer/engineer and artist” 
(2013; p. 2911). Thus, the staging of an appropriate atmosphere in the studio as a space of performance or, put another way the 'tuming' of the studio, centres firmly on the emotional labour of producers and engineers and their ability to create a particular state of mind in musicians that elicits an appropriate 'performance'.

Most accounts of affect and affective atmospheres are premised on a decentring of the individual subject and instead focus on how different configurations of objects, technologies and bodies come together to form different capacities and experiences of relationality (Bissell, 2010; Edensor, 2012). The recent literature on atmosphere has tended to bifurcate between philosophical explorations of the ontology of 'atmosphere' and more tangible and applied empirical studies that focus on the materiality of atmosphere (see for example the special issue of the journal Emotion, Space and Society, Volume 15, 2015), including the 'staging' of atmosphere (see for example Edensor, 2012, 2015). These two strands of work emanate from Böhme (1993) who conceptualises atmosphere as emerging from the intersection of the subjective and the objective. In other words, atmospheres are on one-hand indeterminate in the sense that they are experienced and understood differently (Massumi, 1995) but at the same time they can be materially staged or produced through via-an arrangement of objects and other sensory manipulations (Sørensen, 2015). Inspired by Adey, Brayer, Masson, Murphy, Simpson \& Tixier's (2013) focus on how affects (and emotions) can be collective and transmitted between people, this paper explores 'how' atmospheres are staged beyond the material. Accounts such as that from Watson and Ward (2013) suggest intentionality in the 'doing' of emotions in terms of staging an atmosphere for a particular artistic and/or commercial goal. A focus on emotional labour, we suggest, allows us to bring agency and intentionality into accounts of atmosphere. 


\section{Methodology}

The analysis presented in this-paper is based upon qualitative data from two complimentary qualitative research methods; semi-structured interviews and 'on-set' non-participant observations. The paper forms part of a wider project on emotional labour in spaces of work and performance in the creative industries, for which a total of 33 participants across the music and film industries have been interviewed. Specifically, this paper draws on a sub-set of these interviews undertaken with thirteen independent film directors working in Ireland and the UK. Interviews were elicited by approaching (either by e-mail or in person) film directors who attended three significant independent film festivals in the UK and Ireland in 2012 and 2013. All but one of the interviewees were male, which is in part a reflection of the predominance of male directors present at the festivals, and ranged in age from approximately 20 years to 50 years old.

The length of the-each interviews was on average 45 minutes. The data was transcribed, handcoded, and analysed using a systematic coding and recoding based around key themes and common categories emerging from a thematic analysis of the data considered in relation to the overall theoretical framework. Pseudonyms are used in this paper to protect the anonymity of the interviewees.

In his consideration of methodological issues in emotional research, Sturdy (2003) emphasises that while interviews seek to reveal emotion through recollection and reflection, there can be issues of whether accounts are faithful in recounting emotions, especially sensitive emotions. Further, he emphasises how interviews are unable to capture 'real time' emotion and feeling. Observational methods, on the other hand, offer the opportunity to capture emotion 'in process' and shorter-term emotion dynamics and tensions. Thus, in order to get an 'affective' appreciation of the film set as a space and place of work and performance, an 'on-set' non- 
participant observational study at an independent film shoot in Birmingham, UK, was conducted in 2014. The shoot involved 16 cast members with dialogue, 20 extras without dialogue, and a crew of some 70 individuals. Importantly in terms of our own concern with the role of collective emotional labour in staging particular atmospheres, a cast and crew of this size provided an opportunity to observe inter-personal interactions and 'real time' emotional dynamics on the film set. This methodology proved to be vital in gaining an appreciation of what it is like to work on a film set first-hand. Observations were analysed using the themes that emerged from the earlier qualitative interviews and the extant literature.

The focus on independent film directors represented a methodological decision regarding ease of access to research participants, and it is important to recognise how this decision impacts upon the findings described in this paper. The issues and strategies around emotional labour emphasised in this paper may be very different at the level of professional studio films for a number of reasons. First, in studio productions, it is likely that there would be a greater separation of cast and crew than found in independent film; for example in studio films actors may have trailers or dressing rooms in which they can emotionally prepare for scenes away from the crew, and these are absent in most small-budget independent films. Second, in independent film it is often the case that crew or actors are working for little or no money, and this may impact both on their responsiveness to the leadership of the director, and what the director may be willing to ask of them. Finally, pressures around time and budget may well be rather different, as may the level of emotional investment in the film of the director, cast and crew. These three factors will all likely impact upon the relational dynamics on-set, and thus on 'how' collective emotional labour eceurs and its importance.is performed. 


\section{Directing 'on-set'}

Our observations on set allowed us to sensorially observe how film sets are highly orchestrated and yet simultaneously 'chaotic' spaces populated with a variety of people performing a range of technical, creative and administrative tasks. The experience was one of relentless intensity. The filming that we observed took place in the interior of a public house, and the energy in the room was frenetic; it was loud, busy, hot and cramped. It was imbued with a soundscape of human energy, the moving of equipment and the hum of large fans which battled against the heat of the set lights. When ready for a scene, upon instructions from the director everyone designated as not-essential to performing and shooting that scene would quickly leave the performative space. In the build up to the director calling 'action', all was quiet, in comparison to that which had gone before. In that moment, the space became one focused on the performance. It changed to allow for the actors to perform without distraction and for clear sound recording. Cast, crew and director became focused entirely on what was happening in front of the camera. When filming was complete, at the call of 'cut' from the director, the set once again came alive, as the crew and actors prepared for the next scene to be shot.

The role of the film director within this space is highly complex. Film directors are typically hired by a producer, who oversees administrative management of the production process from a distance, including finance, marketing and distribution. The director is the creative and technical leader of a temporary project team on-set, which is constituted by both performers and technical specialists brought together to produce a film. Film directors must exert a high degree control over the set. Christopher, an experienced independent film director described how "it's a rigidly hierarchical structure and it needs to be... somebody has to say yes or no, this is what's going in the film, this is what's going on in the scene... that is the director's 
role”. Their responsibilities are both artistic and technical; they must manage not only people (cast and crew), but also artistic creativity, storytelling, vision and technical specialty that allows these elements to be depicted on screen. Our observations noted how the film director switched between dealing with the creative elements of filming, for example talking through scenes and dialogue with actors, and the technical elements of film production, such as which lenses would be used and how the set would be lit. Even on independent films, a director is typically supported by Heads of Department (HOD), such as a cinematographer who leads the camera and lighting teams, or a production designer who manages props, wardrobe and make-up artists. These HODs provide vital assistance to the director in balancing technical responsibilities and creative responsibilities. However, ultimately, the director takes responsibility for making all creative and technical decisions' set within the context of the budget, which is controlled by the producer.

It has been noted by Heaney (2006) that the intersectionality between the technical and the creative can often result in a privileging of the technical over all else. Yet, Heaney also notes that the actor-director relationship is key to a successful end product. Through our observations and interviews we came to understand how film directors do not necessarily perceive their work in terms of a technical vs. creative binary, but instead view the film set as a complex relational space that must be carefully managed to elicit high quality technical and creative performances. In the sections that follow, we present accounts from the film directors interviewed, to illustrate how they work within this shared creative and emotional space. Drawing on Hochschild's notion of 'collective emotional labour', we identify three 'relational projects' (Hallqvist, 2012; Wood \& Dibben, 2015) which film directors invest in to elicit 'good' performances: comportment, corpsing and conflict. Through these relational projects we explore the emotional labour taking 
place on the film-set and the ways in which it is used to stage and maintain particular atmospheres, which in turn shape individual and collective performances and actions.

\section{Comportment}

Comportment is derived from the Latin 'comportare' meaning 'to conduct oneself' (Hopfl \& Linstead, 1993). In the context of film production and working on-set, comportment equates to conducting oneself in such a manner as to deliver a successful 'performance', whether this be in artistic or technical terms. In this section, we highlight how film directors are conscious of the importance of the relational project of comportment, both in terms of how they conduct themselves, and how others on set also play a key part in this comportment project. In other words, we demonstrate how the film director not only manages the emotions of the actors en set in their delivery of an appropriate emotional performance in keeping with their character's emotions during particular scenes, but also appreciates the potential impact of their own emotions and the emotions of the crew on this performance, and thus the need to perform emotional labour.

Most of the film directors who participated in this study spoke of their work on set as primarily involving managing their own emotions, the emotions of the crew and the emotions of the actors on and off set. Perhaps insightfully, given Hochschild's (1983) original presentation of the emotional labour construct was through an analysis of air hostesses, Jack drew an interesting parallel between the emotional labour of the director and that of an air stewardess:

I think that you should always keep a lid on that... and like whenever you are on a plane, if you have got turbulence you look at the air stewardesses and if they are panicking then you get really worried, so I think directors are exactly the same. If the 
director has got tense or worried or seems flustered, then everyone else is going to get more flustered. So, you are managing the atmosphere on set, so you have got to keep it [your emotions] within.

Jack's neat-analogy then-is one clearly indicative of his appreciation of the importance of the relational work he is undertaking in his role as director. By 'keeping a lid' on his negative emotions he is able to prevent these 'bad' or negative feelings spreading to others on set. In this way, he is referring to emotional contagion. Astutely, Jack intuits the potentially disruptive influence his own emotions, in his role as director, could have on the atmosphere of the film set. In a bid to prevent his own frustrations, anxieties and worries spreading throughout the cast and crew, Jack is purposefully supressing his own genuinely felt emotions by performing emotional labour. Others we interviewed also recognised that it is not only the emotions of the director that can be contagious, but also that emotions can spread or 'ripple' (Barsade, 2002) between members of the cast and crew. In this regard, a number of interviewees noted the importance of having crew 'on side' in order to prevent a situation where negative and destructive attitudes and emotions rippled out across the film set, especially those aimed at the director. As David describes:

Actors are very vulnerable, and you can’t be their best friend... you have to be pushing them and they're in a vulnerable place... they're looking out for somebody to moan to, and often the crew will facilitate that, "oh he’s so mean”, and... you really have to stop that because then the actors will become, “yeah, he is really mean” and say "actually no I don't want to do that” ... you go for another take and there's a [sigh], that kind of [sigh] and immediately then that just starts a feeding frenzy, once the camera man does it... 
then the actors go [sigh], suddenly you've got a room of people that are all doing that thing, and there's just really fucked up energy on the set.

Such an account mirrors Edensor's (2015) description of the atmosphere of the football stadium,

a similarly physically bounded environment albeit ofat a much larger scale. Edensor describes how 'affective expressions' are communicable across space, transmitted and received by faces, arms, legs, gestures and postures. He notes for example, how "Two or three people might start up a chant, applaud, complain or gesture and a multitude of others instantaneously echo such actions with little reflection” (2015; p. 85). Such expressions and practices then act to co-produce a shift in atmosphere through contagion, highlighting the very dynamic nature of atmospheres. In the case of David's account, his description of a "fucked up energy on the set" suggests a shift in atmosphere such that it now works against, rather than for, the authority of the director and his ability to manage the emotional tone of the set. Here we find the concept of atmosphere useful in challenging the notion of fixed dramaturgical frames; the atmosphere is considered to be "fucked up" because the rules of comportment under which the crew labour and the associated rules of emotional display (Hochschild, 1983) have been broken, that is to say it suggests an erosion of the behavioural and emotional differences between front stage (actors) and backstage (crew). David's reference to "a room of people that are all doing that thing" speaks to a negative atmosphere that has permeated the entirety of the space and effectively erases the notion of a front-back stage divide.

\section{Corpsing}

While David's account emphasises the negative aspects of the co-production of atmosphere, it is also important to recognise the potential positive effects that can derive from this. In other 
situations, the same collective emotional experience may hold considerable value, as is the case in mitigating the risks of corpsing. The term 'corpsing' is one that refers to "occasions on which an actor becomes distracted in performance” (Hopfl \& Linstead, 1993, p. 89). This includes times such as when an actor might be overcome with a fit of laughter; forget their lines; is no longer able to buy into the storyline or character; recognises that an audience is watching them; or is disturbed by a technical error. It is a moment of self-recognition, or put in Goffman's terms, a ‘break' of frame. For Goffman (1959) all social performances require the 'willing suspension of disbelief' from both the actors and the audience, and in the context of the theatre or film set, corpsing, is the exposure of the performance as an orchestrated illusion which can no longer be sustained. Goffman (1974, p. 31) refers to such incidents as "muffings", described as "occasions when the body or some other object assumed to be under assumed guidance, unexpectedly breaks free and deviates from course, or otherwise slips from control... with consequent disruption to orderly life". These muffings have the potential to induce corpsing, and these moments can also be contagious, with a high risk of one actor's corpse revealing others. Thus, film directors invest time and energy into managing the emotions of their actors and crew in this shared emotional space to avoid these moments of frame break which would bring to the fore the recognition that the performance is indeed a performance.

The emotional labour invested in mitigating against corpsing represents another on-set relational project that film directors see as being a significant part of their work. In this regard, many of the directors we interviewed spoke of the important role everyone played on the film set in creating an emotional atmosphere or 'tone' conducive of an appropriate emotional performance in the character's emotional journey. Jack shared his view that: 
... you have to manage the atmosphere very heavily, in that seriously everyone is going to be quite quiet on set, you can't be messing around because it throws the atmosphere off... you are after the moments that really work and finding a way that you can structure the atmosphere on set for someone to be relaxed enough to do that...

Through the explicit use of the term 'atmosphere' Jack is intimating his awareness of providing a conducive environment, or emotional space, which allows actors to 'self-transform' (Roach, 1985) the self into another, that of the character. Stanislavski (1937, p. 180) notes that the external production of a play is "inwardly tied up with the spiritual life of the actors" and that if it "produces the right mood it helps the actor to formulate the inner aspect of his role, it influences his whole psychic state and capacity to feel”. As Tan (1996) describes, the actor must be able to display the appropriate emotions for the character, that is to say provide an intelligible and believable performance set in the context of the narrative of the film, for the viewing subject to also experience a range of appropriate empathetic emotions. Further, Tan notes that many films, such as melodramas, "provide an opportunity to study the emotions of a character in greater depth” (1996; p. 183), thus placing even greater emphasis on the ability of the actor to formulate the inner aspect of their role. The appropriate atmosphere that enables them to do this, of course, is not static; instead it will shift to reflect the scene being filmed at any one time. The atmosphere required on the set will be very different when shooting a party scene compared to a death scene, for example. Depending on the sequence of shooting, scenes which place demanding and often very different emotional requirements may quickly follow each other and thus the work of the directors in providing the appropriate atmosphere for a particular performance is crucial. 
The staging of an atmosphere is however not just the responsibility of the director and the actors. The crew too needs to be complicit in the performance. Again, here we find the concept of atmosphere useful in challenging the static nature of dramaturgical frames. Goffman (1959, p. 130) for example notes that "individuals can transform any region into a backstage" just by invoking a backstage style”. Yet, in the case of the film set at least, the notion of defined and distinct front and back stage 'styles' maintains an artificial binary separation between the emotional display rules between cast and crew. Rather, atmospheres are collectively staged and collectively maintained, simultaneously being the extendedness of the moods of those on the set and attuning their moods (Edensor, 2015) as appropriate to a particular scene. As Louise, explained, “as professionals everybody knows when you're coming up to a big scene that it's a different atmosphere on set, and everybody just goes back and is very quiet and very respectful of what's actually happening in front of the camera". Further, as Heaney suggests "it is the director's role to provide vision and encourage all participants actively to contribute, both to the concept and the production" and that "this is best achieved through a keen focus on the actor and providing a safe and supportive environment” (2006, p. 224; emphasis in original). As Kevin explains, "They [the crew] know that if there’s something very emotional coming up and very serious coming up... you know you can see it in their eyes that they are thinking about it and you can’t distract them”.

The creation of the appropriate atmosphere on the set involves being sensitive to the emotions of an actor not just during moments of performance, but at all times. Directors recognise that emotions not only occur at the point of the performance; they are also present during the preparation for a performance, and after the performance has taken place. In performance spaces such as theatres, dressing rooms and the liminal space of the wings provide 
“temporary shelter from the exposure of the stage" (Wulff, 1998, p. 113), spaces where performers can wait and prepare out of sight of their audience. The lack of such spaces on smallbudget film sets provides a particular set of challenges to actors in their preparations for scenes, and thus to the directors. Robert gave an example of a particularly sensitive scene being filmed in a piece on the Auschwitz death camp, and described the way in which they had "tiptoed" around the actress on the set prior to filming the scene in order to give her some space and allow her to "be in the moment, to be there" and mentally and emotional prepare herself for the performance. Louise described how she had helped to prepare actors for particularly challenging scenes, either through talking through the scenes with the actors or giving them the emotional 'space’ to prepare for the performance:

If you're coming up to a big scene definitely you need quiet time and if you're, say, shooting on a location where you don't have a trailer, you don't have time to get focussed into this particular place that you need to be then the crew need to respect that and that's the director's role to tell everybody to just, “look keep it quiet he needs some concentration here, he needs time and space to get his head together for this scene”.

Both quotes suggest that directors are highly sensitive to the personal emotions of actors as they prepare for, and perform emotionally-charged scenes. Indeed, Louise noted that the emotions and needs of the actors come above those of all others: “...fuck everybody on set... no it really it, it has to be about them and their sensitivity". Through this account, we hear the hierarchy of emotional importance-.being revealed. Indeed, it is clear that the emotional portrayal of the character is privileged over all else, and thus, the crew must recognise this hierarchy and be complicit in the construction of an atmosphere conducive of the desired performance on set. At other times, however, the atmosphere on set may contrast that of the scene, such as when actors 
and crew create an atmosphere of laugher to diffuse attention associated with particularly tense or intimate scenes (see for example Ince, 2006). Here, collective emotional labour is then used as a form of coping and support mechanism (Hochschild, 1983; Korczynski, 2003).

Emotional performances can of course have a significant personal emotional impact on actors. Stanislavski’s (1937) concept of ‘emotional memory’ emphasises how actors draw on one's own lived experiences and emotional memories in a way which enables them to relive sensations and emotions analogous to their roles. This is closely associated, and indeed, largely the inspiration for, Hochschild’s ‘deep acting' (1983). Through tracing their own emotions back to the original stimulus, actors can repeat a desired sensation to weave "the soul of the person he is to portray out of emotions that are dearer to him than everyday sensations" (Stanislavski, 1937, p. 176). This requires the actors to vividly relive past emotions, the demands of which were recognised by many of the directors we interviewed, with David for example noting how:

I prepare the actors now for that kind of thing and just be honest with them and say look, it's going to be hard, it is very hard on them, because I do really push them, especially if there's emotional stuff in it ... a lot of discussion about how intense it's going to be or how draining it's going to be for them and how you expect them to go there and to go to that place and to engage with that.

In some cases, emotions can become so heightened as to represent their own form of corpsing, in what Goffman (1974, p. 566) terms a "genuine flooding out” of emotion. Kevin for example spoke of a particular actress who had been particularly affected by a character she played: ...there was something very raw about her, you know something very raw and very emotional about her and actually... she became pregnant with emotion actually... like you know try and talk about the script and sometimes she'd start to cry. And we'd have to 
stop and she just really was attached to this character you know... Sometimes you go,

“less tears” and she says “I can’t help it, I can’t help it”.

But such heightened emotions are not just limited to the actors. Directors are also exposed to the emotions of the atmosphere and performances they work to create on set, often empathising strongly with the emotions of a performance. Christopher described how "I just spent every morning weeping... And [actor's name omitted] made me ... he was doing his death scene and I literally I could not call 'cut' at the end”, while Robert explained how: “...you're there with them... a good director is right beside the camera, just off the side of the camera watching it and empathising with the actor. That's why it's so draining." This empathy allows directors to understand and respond to the emotional needs of actors in particular situations but more importantly, this highly empathetic emotional tone is designed to reduce the potential for corpsing. However, perhaps an often more pressing and real concern for directors was the potential for conflict on set, such that they invested heavily in managing relations to avoid such encounters.

\section{Conflict}

While directors may work to avoid upsetting either the cast or crew, in order to maintain harmony on set and thereby mitigate risks of 'corpsing' for the actors, many of the directors we interviewed recognised that conflict was as an inevitable part of the creative process of film making. As Hodge (2009, p. 20) notes, “creative, collaborative relationships will inevitably involve some degree of conflict because there is passion and investment on all sides”. Much like other spaces of collaborative creative production, film sets are spaces of highly intensive, timepressured work, as David describes: 
There's going to be days where they're going to hate you because you're really $f^{* *}$ king pushing them and it's all great to start and everyone's really excited but once you get into fucking four o'clock in the morning... and you're going for take fifteen, they just want to $\mathrm{f}^{* *}$ king hit you, they hate you and they won’t talk to you for two days afterwards, and so you have to endure that.

Conflict on the film set can take a number of forms, from the constructive creative conflict involved in the passionate exchange of ideas; to situations when people are felt not to be performing sufficiently in their role; to the sometimes damaging conflict resulting from personality clashes. This makes the relational project of conflict management a significant part of film directing work.

Bechky (2006) notes that while frustration and private complaints are particularly common on the film set, they tend to be "polished into more polite admonishing in public" (2006, p. 14). This was supported by Mark, who suggest that, "it's giving out the vibe that ... if things are going bad, it's not ... I'm going to be fucking grumpy and stressed, it's explaining look guys, we're doing this now, this has happened, here's what we should do now”. In other words, Mark is describing how he supresses his own 'grumpiness' and 'stress' by attempting to manage his own emotions, in a bid to avoid the contagion of his own negative emotions to others on set. This suppression of feelings also, importantly, permits the director to maintain an image of being in control. Heaney suggests that "actors can be very intimidating and in my experience quite merciless when detecting insecurity in a director” (2006, p. 225). Supporting Heaney’s assertion, it was common amongst the interviewees to talk about being 'tested' by certain members of the cast and crew, with David noting that "there's a weird thing where they try to test you, try to test your resolve and want to see what they can get away with, and how much 
they can $\mathrm{f}^{* *} \mathrm{k}$ with you”. In this context, emotional labour is employed as a form of conflict avoidance. As Bodtker and Jameson (2001) suggest, many people prefer to avoid conflict, with conflict being an emotionally charged state that is uncomfortable due to its accompanying emotion. Indeed, while all of the interviewees recognised that emotions were an inevitable part of film making, many found the emotional elements of their job highly uncomfortable, particularly when these emotions were challenging and difficult. As David explained, "I found that really hard because I don't like not being liked, I get really distracted then on set, I can't concentrate on the scene because I know they're all really annoyed with me.”

However, other interviewees suggested that cast or crew members may take advantage of, or not respect, a seemingly weak personality, and as such a strategy of appeasement is ineffective. As Bodtker and Jameson (2001) suggest, the preconceived nature of the relationship between parties - in this case that the director should be confident and firmly in control - frames the meaning of emotional communication, and subsequent emotional communication challenges of reaffirms this relations definition. As such, a number of interviewees suggested that the only way such a situation can be resolved is through a 'show of strength' on the part of the director, as is highlighted in the experience described by Ben:

I was Mr. Nice, I tried to make everybody happy and they turned against me and it’s stupid... it seems to be human nature that you have to be alpha and you have to clip them on the ears and when you do that they're as happy as anything and I don't get it, I don't understand it but I know the result of doing it and it works and they will follow you into hell when you do it. But if you try to make everybody happy they will eat you up, they will tear you apart.... 
Ben went on to describe how "on my first film it almost came to blows between me and a crew member who was just poisoning the set and mistreating my other crew members. Just arrogant and nasty”. The analogy of a 'poison' used by Ben once again acknowledges an implicit awareness of the importance and value of collective emotional labour on set to the staging of an atmosphere and both the value and dangers of emotional contagion (Barsade, 2002) in this regard.

Yet, our own observations of film directing, along with those of Beckhy (2006) suggest that even during heavily pressurised periods of filming, anger is very rarely displayed. However, as Bodtker and Jameson (2001) note, power is a key relational element, and therefore where the director feels that -their authority is being directly challenged, conflict is highly likely to be triggered, that is to say, they become “emotionally activated” (2001, p. 260). Kevin for example noted that the way in which he felt 'tested' has in the past elicited very strong angry emotions:

There have been a couple of times when I've ended up screaming at somebody... I turned round and screamed at them and told them you know that they are " $\mathrm{f}^{* *}$ king well out of order”... and then they stopped and kind of like looked at me as if like “okay, now I see how far I’ve pushed this guy” and then, from then on they’ve been as good as church mice. It's a shame it had to get to that.”

From their own study of film directors, Coget et al. (2011) suggest that, where feelings of high anger are expressed leadership effectiveness can be compromised, especially where anger hinders the development of inter-personal relationships (see also George, 2000). Certainly, our interviews and observations suggest there to be a high level of emotional control amongst directors, and a verbalised awareness of the potentially damaging consequences of such emotional displays to the atmosphere on set. By its very nature, conflict is emotionally charged, 
and as Gardner, Fischer \& Hunt (2009) assert, negative-effective events produce higher requirements for emotional labour. In other words, post-conflict emotions will also require significant management if the director is going to repair the atmosphere on set. Yet, we also note that for some, expression of anger acted in-part to resolve negative situations through an effective 'show of strength', acting to reaffirm the directors hierarchical position to cast and crew. In such cases, the expression of anger cannot be seen solely in terms of representing a failure to abide by the associated display and feeling rules (Hochschild, 1979) or a form of “unintentional self-disclosure” (Goffman, 1974, p. 572). Rather, expressions of anger and outrage can also represent a partly responsive, partly conscious strategy of antipathetic emotional labour (Korczysnki, 2003; Ward \& McMurray, 2016). Thus, it represents an appropriate emotional display for the situation in order to respond to 'tests' of integrity and ability, and to create a favourable impression of, and trust in, the director as creative leader. In this way, then, conflict can be framed as a significant relational project that is used to build trust and respect between director, cast and crew, which ultimately underpins their ability and authority to orchestrate the set and stage and maintain atmospheres conducive of the desired emotional performances.

\section{Conclusion}

While theories of affect and of atmosphere have tended to decentre the individual human subject and privilege the relational (Edensor, 2012), our analysis draws attention to the importance of agency and intentionality in the staging of atmospheres. Through our findings, we have demonstrated how film directors direct not only the filming, but also orchestrate the atmosphere of the set, actively staging, maintaining and altering the practices of those working within them. 
Yet, our analysis has also demonstrated that the relational and collective remain central to the notion of atmosphere, with the director relying on the collective emotional labour (Hochschild, 1983) of both cast and crew on the set to create and maintain an atmosphere conducive of emotional performances in front of the camera. This in turn illicits appropriate emotional responses from the audience (Tan, 1996). We have identified three relational projects comportment, corpsing and conflict - through which film directors attempt to manage their own emotions and the emotions of cast and crew. There are both artistic and commercial reasons underpinning this labour: it is set against a backdrop of social and emotional relations, creative inter-personal collaboration and conflict, technical challenges, leadership and the management of tight budgets and deadline.

Conceptually, we have identified how the concept of atmosphere offers a critique of Goffman’s bounded dramaturgical frames of front-back stage. As Bille et al. (2015) argue, atmospheres are instrumental in rubbing out the boundaries of their various components; in the case of the film set, it is a singular emotional space in which cast and crew alike are required to uphold particular atmospheres on-set, regardless of whether they are in front of or behind the camera. Reading the relational space of the film set in this way thus blurs the lines between Goffman's front and back stage regions. Rather, the displays, meanings, actions and negotiations that occupy these spaces proliferate in complex ways that are not limited to fixed frames but ratherwhich involve collective emotional labour in a single shared creative workspace.

Our broader aim has been to demonstrate how the application of the emotional labour construct to geographical debates regarding atmospheres can contribute new insights in to ways in which atmosphere are staged, for what reasons, and by whom. Whilst it is understood that the "doing of emotions" (Katz, 2000, p. 22) is an active outcome of encounters, we go further to 
suggest that this relational 'doing' often has intentionality. Individual and collective emotional labour is used to intentionally stage atmospheres, which in turn shape individual and collective emotion and action. Through displays (or non-displays) of emotion and emotional labour, atmospheres can be created, maintained, manipulated, and disrupted. Atmospheres are not then fixed and static, but pliable, unpredictable, dynamic, and emergent (McCormack, 2008; Anderson, 2009). Indeed, as Thrift (2006) notes, every space is in constant motion, despite attempts to make space static and stable. In this context, we see emotional labour, at least in part, as a collective attempt to create and maintain momentarily static atmospheres for particular performances, in particular scenes, with particular emotionsaffect. Yet from scene to scene, the emotional requirements of a performance may shift, and-thes so too must the atmosphere. As Wetherell (2012) argues, atmospheres are actively created and need work to sustain. Thus, in this context, individual and collective emotional labour represents a "more or less skilled response to the arrangement of things, a sense of propensity of the situation” (Thrift, 2006, p. 144). It is not then simply the actor's performance that stages the atmosphere on set, but rather the collective emotional performance of all on set.

\section{Acknowledgements}

The authors are grateful to John Harrison, Sarah Mills, and the three anonymous reviewers, whose insightful and constructive critiques have greatly improved the clarity of the arguments

presented in this paper. Thanks also to the film directors who so kindly gave their time to take part in research interviews.

\section{References}


Adey, P., Brayer, L., Masson, D., Murphy, P., Simpson, P. \& Tixier, N. (2013). 'Pour votre tranquillité’: Ambiance, atmosphere, and surveillance. Geoforum, 49, 299-309.

Anderson, B. (2009). Affective atmospheres. Emotion, Space and Society, 2, 77-81.

Anderson, K., \& Smith, S. J. (2001). Editorial: Emotional geographies. Transactions of the Institute of British Geographers, 26, 7-10.

Ash, J. (2013). Rethinking affective atmospheres: Technology, perturbation and space times of the non-human. Geoforum, 49, 20-28.

Barsade, S. G. (2002). The ripple effect: Emotional contagion and its influence on group behaviour. Administrative Science Quarterly, 47, 644-675.

Batnitzky, A., \& McDowell, L. (2011). Migration, nursing, institutional discrimination and emotional/affective labour: ethnicity and labour stratification in the UK National Health Service. Social and Cultural Geography, 12, 181-201.

Bechky, B. A. (2006). Gaffers, gofers and grips: role-based coordination in temporary organizations. Organizations Science, 17, 3-21.

Bille, M., Bjerregaard, P. \& Sørenson, T. F. (2015). Staging atmospheres: materiality, culture, and the texture of in-between. Emotion, Space and Society, 15, 31-38.

Bissell, D. (2010). Passenger mobilities: affective atmospheres and the sociality of public transport. Environment and Planning D: Society and Space, 28, 270-289.

Blumer, H. (1969). Symbolic interactionism: Perspective and method. Englewood Cliffs, NJ: Prentice-Hall. 
Bodtker, A. M., \& Jameson, J. K. (2001). Emotion in conflict formation and its transformation: application to organizational conflict management. The International Journal of Conflict Management, 12, 259-275.

Böhme, G. (1993). Atmosphere as the fundamental concept of a new aesthetics. Thesis Eleven, 36, 113-126.

Böhme, G. (2013). The art of the stage set as paradigm for an aesthetics of atmospheres. Ambiance: International Journal of Sensory Environment, Architecture and Urban Space, 2013, no pagination. Retrieved from http://ambiances.revues.org/315.

Bolton, S. (2001). Changing faces: Nurses as emotional jugglers. Sociology of Health \& Illness 23, 85-100.

Bondi, L. (2005). Making connections and thinking through emotions: Between geography and psychotherapy. Transactions of the Institute of British Geographers, 30, 433-48.

Bryson, J. R. (2007). The 'second' global shift: the offshoring or global sourcing of corporate services and the rise of distanciated emotional labour. Geografiska Annaler: Series B, Human Geography, 89, 31-43.

Clarke, D. B. \& Doel, M. A. (2007). Shooting space, tracking time: the city from animated photography to vernacular relativity. Cultural Geographies, 14, 589-609.

Coget, J. F., Haag, C., \& Gibson, D. E. (2011). Anger and fear in decision-making: The case of film directors on set. European Management Journal, 29, 476-490.

Conradson, D., \& Latham, A. (2007). The affective possibilities of London: Antipodean transnationals and the overseas experience. Mobilities, 2, 231-254. 
Crang, P. (1994). It’s showtime: On the workplace geographies of display in a restaurant in Southeast England. Environment and Planning D: Society and Space, 12, 675-704.

Davidson, J., \& Bondi, L. (2004). Spatialising affect; affecting space: An introduction. Gender, Place and Culture, 11, 373-74.

Davidson, J., \& Milligan, C. (2004). Embodying emotion sensing space: Introducing emotional geographies. Social and Cultural Geography, 5, 523-532.

Davidson. J., Bondi, L., \& Smith, M. (Eds.). (2005). Emotional geographies. Aldershot: Ashgate.

Dodds, K. (2013). 'I'm still not crossing that': Borders, dispossession, and sovereignty in Frozen River (2008). Geopolitics, 18, 560-583.

Doel, M. A., \& Clarke, D. B. (2007). Afterimages. Environment and Planning D: Society and Space, 25, 890-910.

Duffy, M., Waitt, G., Gorman-Murray, A., \& Gibson, C. (2011). Bodily rhythms: corporeal capacities to engage with festival spaces. Emotion, Space and Society, 4, 17-24.

Dyer, S., McDowell, L., \& Batnitzky, A. (2008). Emotional labour/body work: The caring labours of migrants in the UK’s National Health Service. Geoforum, 39, 2030-2038.

Edensor, T. (2012). Illuminated atmospheres: Anticipating and reproducing the flow of affective experience in Blackpool. Environment and Planning D: Society and Space, 30, 1103-1122.

Edensor, T. (2015). Producing atmospheres at the match: Fan cultures, commercialisation and mood management in English football. Emotion, Space and Society, 15, 82-89. 
Ekman, P. (1973). Cross culture studies of facial expressions. In P. Ekman (Ed.), Darwin and facial expressions: A century of research in review (pp. 169-233). New York: Academic Press.

Gardner, W. L., Fischer, D., \& Hunt, J. G. (2009). Emotional labor and leadership: A threat to authenticity? The Leadership Quarterly, 20, 466-482.

George, J. M. (2000). Emotions and leadership: The role of emotional intelligence. Human Relations, 53, 1027-1055.

Goffman, E. (1959). The Presentation of Self in Everyday Life. London: Penguin.

Goffman, E. (1974). Frame analysis: An essay on the organization of experience. Boston, MA: Northeastern University Press.

Grindstaff, L. (2002). The money shot: Trash, class, and the making of TV talk shows. Chicago, IL: University of Chicago Press.

Hallqvist, A. (2012). Occupational transitions as a relational project. Studies in Continuing Education, 34, 83-98.

Heaney, B. (2006). Cross-pollinating skills: Directing for theatre, television and film. South African Theatre Journal, 20, 221-232.

Hesmondhalgh, D., \& Baker, S. (2008). Creative work and emotional labour in the television industry. Theory, Culture \& Society 25, 97-118.

Hochschild, A. R. (1979). Emotion work, feeling rules, and social structure. The American Journal of Sociology, 85, 551-575. 
Hochschild, A. R. (1983). The managed heart: Commercialisation of human feeling.

Berkeley, CA: University of California Press.

Hodge, C. (2009). Film collaboration and creative conflict. Journal of Film and Video, 61, 1830.

Hopfl, H., \& Linstead, S. A. (1993). Passion and performance: Suffering and the carrying of organizational roles. In. S. Fineman (Ed.), Emotions in Organisations (pp. 76-93). London: Sage.

Ince, K. (2006). Is sex comedy or tragedy? Directing desire and female auteurship in the cinema of Catherine Breillat. Journal of Aesthetics and Art Criticism, 64, 157-164.

Isenbarger, L., \& Zembylas, M. (2006). The emotional labour of caring in teaching. Teaching and Teacher Education, 22, 120-134.

Katz, J. (2000). How emotions work. Chicago, IL: Chicago University Press.

Konijn, E. A. (1991). What's on between the actor and his audience? Empirical analysis of emotion processes in the theatre. In G. D. Wilson (Ed.), Psychology and performing arts (pp. 59-74). Amsterdam: Swets \& Zeitlinger.

Korczynski, M. (2003). Communities of coping: collective emotional labour in service work. Organization, 10, 55-79.

Kruml, S. M., \& Geddes, D. (2000). Exploring the dimensions of emotional labour: The heart of Hochschild's work. Management Communication Quarterly, 14, 8-49.

Lukinbeal, C. (2012). “On location” filming in San Diego County from 1985-2005: How a cinematic landscape is formed through incorporative tasks and represented 
through mapped inscriptions. Annals of the Association of American Geographers, 102, 171-190.

Massumi, B. (1995). The autonomy of affect. Cultural Critique, 31, pp. 83-109.

Mathews, V. (2010). Set appeal: Film space and urban redevelopment. Social \& Cultural Geography, 11, 171-190.

Mayer, V. (2011). Below the line: Producers and production studies in the new television economy. Durham, NC: Duke University Press.

McCormack, D. (2008). Engineering affective atmospheres: On the moving geographies of the 1897 Andree expedition. Cultural Geographies, 15, 413-430.

McDowell, L. (2001). Men, management and multiple masculinities in organisations. Geoforum, 32, 181-198.

McMurray, R., \& Ward, J. (2014). ‘Why would you want to do that?’: Defining emotional dirty work. Human Relations, 67, 1123-1143.

Morton, F. (2005). Performing ethnography: Irish traditional music sessions and the new methodological spaces. Social and Cultural Geography, 6, 1-676.

Ostrowska, D. (2010). Magic, emotions and film producers: Unlocking the "black-box" of film production. Wide Screen, 2, no pagination. Retrieved from http://www/widescreenjournal.org

Pile, S. (2010). Emotions and affect in recent human geography. Transaction of the Institute of British Geographers, 35, 5-20. 
Roach, J. R. (1985). The player's passion: Studies in the science of acting. Ann Arbor, MI: University of Michigan Press.

Shannon, J. H. (2003). Emotion, performance, and temporality in Arab music: Reflections on Tarab. Cultural Anthropology, 18, 72-98.

Sharma, U., \& Black, P. (2001). Look good, feel better: Beauty therapy as emotional labour. Sociology 35, 913-931.

Sharp, L., \& Lukinbeal, C. (2015). Film geography: A review and prospectus. In S. Mains, J. Cupples, \& C. Lukinbeal (Eds.), Mediated geographies and geographies of media (pp. 21-35). Heidelberg: Springer.

Smith, M., Davidson, J., Cameron, L., \& Bondi, L. (Eds.). (2009). Emotion, place and culture. Aldershot: Ashgate.

Soronen, A. (2018). Emotional labour in magazine work: Suppressing and evoking emotions as part of project-based teamwork. Journalism Practice, 12, 290-307.

Sørensen, T. S. (2015). More than a feeling: Towards an archaeology of atmosphere. Emotion, Space and Society, 15, 64-73.

Stanislavski, K. (1937). An actor prepares. London: Eyre Methuen.

Sturdy, A. (2003). Knowing the unknowable? A discussion of methodological and theoretical in emotion research and organisational studies. Organization Articles, 10, 81-105.

Tan, E. S. (1996). Emotion and the structure of narrative film: Film as an emotion machine. New York: Routledge. 
Thien, D. (2005). After or beyond feeling? A consideration of affect and emotion in geography. Area, 37, 450-456.

Thrift, N. (2004). Intensities of feeling: towards a spatial politics of affect. Geografiska Annaler, Series B, 86, 57-78.

Thrift, N. (2006). Space. Theory, Culture and Society, 23, 139-146.

Thrift, N. (2008). Non-representational theory: Space. Politics. Affect. London: Routledge.

Ward, J., \& McMurray, R. (2011). The unspoken work of general practitioner receptionists: A re-examination of emotion management in primary care. Social Science \& Medicine, 72, 1583-1587.

Ward, J., \& McMurray, R. (2016). The dark side of emotional labour. London: Routledge.

Watson, A., \& Ward, J. (2013). Creating the right 'vibe': emotional labour and musical performance in the recording studio. Environment and Planning A, 45, 2904-2918.

Wellington, C. A., \& Bryson, J. R. (2001). At face value? Image consultancy, emotional labour and professional work. Sociology, 35, 933-946.

Wetherell, M. (2012). Affect and emotion: A new social science understanding. Sage: London. Wood, M., \& Dibben, M. (2015). Leadership as relational process. Process Studies, 44, 24-47.

Wulff, H. (1998). Perspectives towards ballet performance: exploring, repairing and maintaining frames. In F. Hughes-Freeland (Ed.), Ritual, performance, media (pp. 104-120). London: Routledge. 